\title{
ARBETSBEHOVET OCH PA DET PÅVERKANDE FAKTORER VID RADMYLLNING OCH KOMBINERAD RADMYLLNING OCH SÅDD
}

\author{
Aarne Pehkonen \\ Institutionen för lantbrukets arbetsteknik vid Helsingfors Universitet \\ Mottaget 16. 7. 1971 \\ LABOUR REQUIREMENT AND AFFECTING FACTORS IN FERTILIZER PLA-
CEMENT AND COMBINE DRILLING
}

Aarne Pehkonen

Department of Agricultural Engineering University of Helsinki

\begin{abstract}
According to the work studies carried out in the years 1968-70, the average labour requirement in fertilizer placement was $51 \mathrm{~min} / \mathrm{ha}$ and in combine drilling $70 \mathrm{~min} / \mathrm{ha}$. In both jobs the effective time, driving with coulters down, was below $50 \%$ of the field working time. The speed has obviously affected the output of the work, more than the working width of the implemens. The driver has apparently infleuenced the selection of the speed. In addition to the driving time, the time required for turning and filling has influenced the output of the work. These three make up about $80 \%$ of the field working time. The speed to turn a machine combination was not found to be dependent on the way the implement was pulled by the tractor (tractor mounted or trailed). On the other hand the skill of the driver affects the turning time. The work input of a worker influences the filling speed. In filling, team work ( $2-3$ persons) has increased the labour consumption ( $\mathrm{min} / 100 \mathrm{~kg} /$ man) on an average from 1.61 to $2.54 \mathrm{~min}$. Time per a quantity in filling decreases while the quantities increase. This is due to the diminishing of the relative share of the start-up and shut-down times. Acording to the studies, it is possible to increase the work output in fertilizer placement and combine drilling mainly in the folloving ways: decrease the labour consumption of effective time by increasing the working width and/or speed of the machine combination, and/or increase the relative share of the effective time in the total field time by reducing unproductive times.
\end{abstract}

\section{Undersökningens utförande}

För att utreda arbetsbehovet och faktorer, som påverkar detta vid radmyllning och kombinerad radmyllning och sådd, utfördes arbetsstudier åren 1968-69 i normalt fältmässigt arbete vid sex nyländska gårdar. Ovannämnda studier omfattar ca 180 ha radmyllning, kombinerad radmyllning och sådd eller sådd. Dessutom utfördes ännu våren 1970 endel gransknings- och jämförelsestudier. Förutom en figur på 2 ha gjordes undersökningarna på täckdikade fält. Den genomsnittliga figurstorleken var vid radmyllning 3.2 
Tabell 1. De viktigaste tekniska data om undersökningsmaskinerna.

Table 1. Technical data on the machines used in the work studies.

Undersökningsmaskinerna

The machines used in the work studies
Maskin typ
Machine type

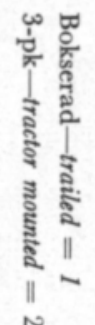

Lådorna 1

Hoppers 1
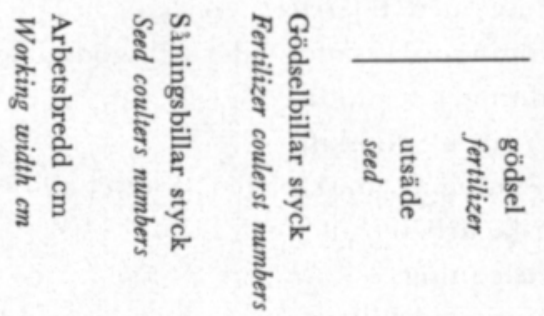

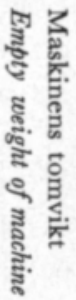

\section{Radmyllare \\ Fetilizer drills Juko-15 \\ Jussi-Junkkari ${ }^{1}$ ) \\ RM-300 \\ Tume-315 \\ Kombimaskiner \\ Combine drills
Antti $^{2}$ )
HS-MK-Combi
Juko
Junnila ${ }^{3}$ )
Nasta-Tume
Pisto

Såmaskiner

Grain drills

Tive-HS

$\begin{array}{ll}2 & 250 \\ 2 & 245 \\ 2 & 250 \\ 2 & 315\end{array}$

-
-
-

15

- 350

560

16

- 250

400

$19 \quad 250 \quad 550$

$19 \quad-\quad 600 \quad 510$

$\begin{array}{rrrrrrr}1 & 250 & 21 & 15 & 280 & 550 & 800 \\ 1 & 276 & 23 & 23 & 770 & 600 & 2500 \\ 2 & 250 & 20 & 10 & 250 & 330 & 890 \\ 1 & 250 & 21 & 15 & 280 & 350 & 1700 \\ 1 & 250 & 21 & 17 & 260 & 280 & 1360 \\ 2 & 204 & 15 & 15 & 200 & 275 & 500\end{array}$

1) Junkkari-gödselspridare försedd med Jussi-radmyllningshjälpanordning

Junkkari-fertilizer distributor with Jussi-fertilizer drilling implement

${ }^{2}$ ) Kombination med Antti-radmyllare och Juko-såmaskin

Combination with Antti-fertilizer drill and Juko-grain drill

3) Kombination med Juko-radmyllare och Juko-såmaskin

Combination with Juko-fertilizer drill and Juko-grain drill

ha och vid kombinerad radmyllning och sådd 2.8 ha, varför arbetsförhållandena kan i detta sammanhang anses ha varit relativt goda.

Ur tabell 1 framgår de maskiner, vilka deltagit i undersökningen. Åren 1968-69var maskinerna ännu delvis på prototypstadiet. I detta sammanhang bör dessa maskiner därför ej betraktas som företrädare för vissa maskinmärken, utan såsom representanter för en viss maskintyp. På grund av detta togs i undersökningen med även en bokserad såmaskin. Den motsvarar både till storlek och köregenskaper en kombimaskin med liten jordbearbetningsförmåga. Denna sistnämnda maskintyp var inte med i undersökningen. 
Undersökningen begränsades till att omfatta endast radmyllning och kombinerad radmyllning och sådd. Den tid, under vilken själva arbetet förberedes, den s.k. ställtiden, har lämnats utanför undersökningen. Den del av den totala tiden, som utgör undersökningsobjekt, kallas operationstid (t.ex. PukкıLA 1959, s. 87).

Operationstiden har indelats i följande olika arbetsskeden:

1. körning med billarna i jorden = körning

2. påfyllning av utsädes- eller/och gödsellåda = påfyllning

3. vändning i tegända = vändning

4. justering av maskin = justering

5. granskning av maskin eller kvalitet av det utförda arbetet

$=$ granskning

6. arbetsledning

$=$ arbetsledning

7. körning med billarna upp vid passerande av hinder eller körning till eller från påfyllningsplatsen

8. avbrott på grund av olika störningar

$=$ tomgång

= störning

9. avbrott på grund av mänskliga faktorer = paus

\section{Arbetsbehovet}

Arbetsbehovet är beroende av många olika faktorer. Verkningsgraden av alla dessa kunde man inte fastställa i undersökningen tillräckligt noggrannt. De största svårigheterna uppstod vid fastställandet av de mänskliga faktorerna.

Det genomsnittliga arbetsbehovet och dess spridning vid radmyllning och kombinerad radmyllning och sådd framgår ur tabell 2. Dessa tal bör ej betraktas såsom allmängiltiga normtal, utan de motsvarar endast arbetsbehovet under försöksförhållandena. Arbetsbehovet har i medeltal varit vid radmyllning $51 \mathrm{~min} /$ ha och vid kombinerad radmyllning och sådd $70 \mathrm{~min} /$ ha. Huvudtiden, d.v.s. körning med billarna i jorden, har vid bägge arbetsoperationer varit i medeltal mindre än $50 \%$ av operationstiden. Arbetsbehovet överensstämmer med motsvarande tal i liknande undersökningar (Jonsson 1969 och SIPILÄ 1969).

Angående körningen avviker resultaten mellan de olika maskinerna relativt sätt minst från varandra (kombimaskinerna $\mathrm{v}=11.6 \%$ och radmyllarna $\mathrm{v}=6.7 \%$ ), fastän tydliga skillnader i maskinernas arbetsbredd förelåg, såsom det framgår ur tabell 1. Speciellt bör man observera, att den till arbetsbredden bredaste kombimaskinens $(276 \mathrm{~cm})$ körningstid var i medeltal ca $2 \mathrm{~min} /$ ha större än den smalaste maskinens (204 cm) körningstid. På grund av detta resultat kan man draga den slutsatsen, att i praktiken inte endast maskinens arbetsbredd allena avgör körningstiden, utan hastigheten spelar härvidlag en avgörande roll. Detta fenomen kan i vissa avseende anses motsvara »lagen om minskande produktionsfaktorer» (jämför t.ex. BARNEs m.fl. och Jonsson 1968).

Om spridningen vid påfyllningstiden kan konstateras, att den i de relativa arbetsbehovstalen ( $v=23.4 \%$ och $7.7 \%$ ) varit mindre än i de absoluta talen ( $v=31.1 \%$ och $17.1 \%$ ). Enligt undersökningen återspeglar spridningen i de absoluta påfyllningstiderna på operationstiden, varvid de relativa tiderna (\%) varierar mindre än de absoluta (min/ ha). Ett motsvarande fenomen förekommer i vändningarna och i tomgången, om dock ej lika markant. 


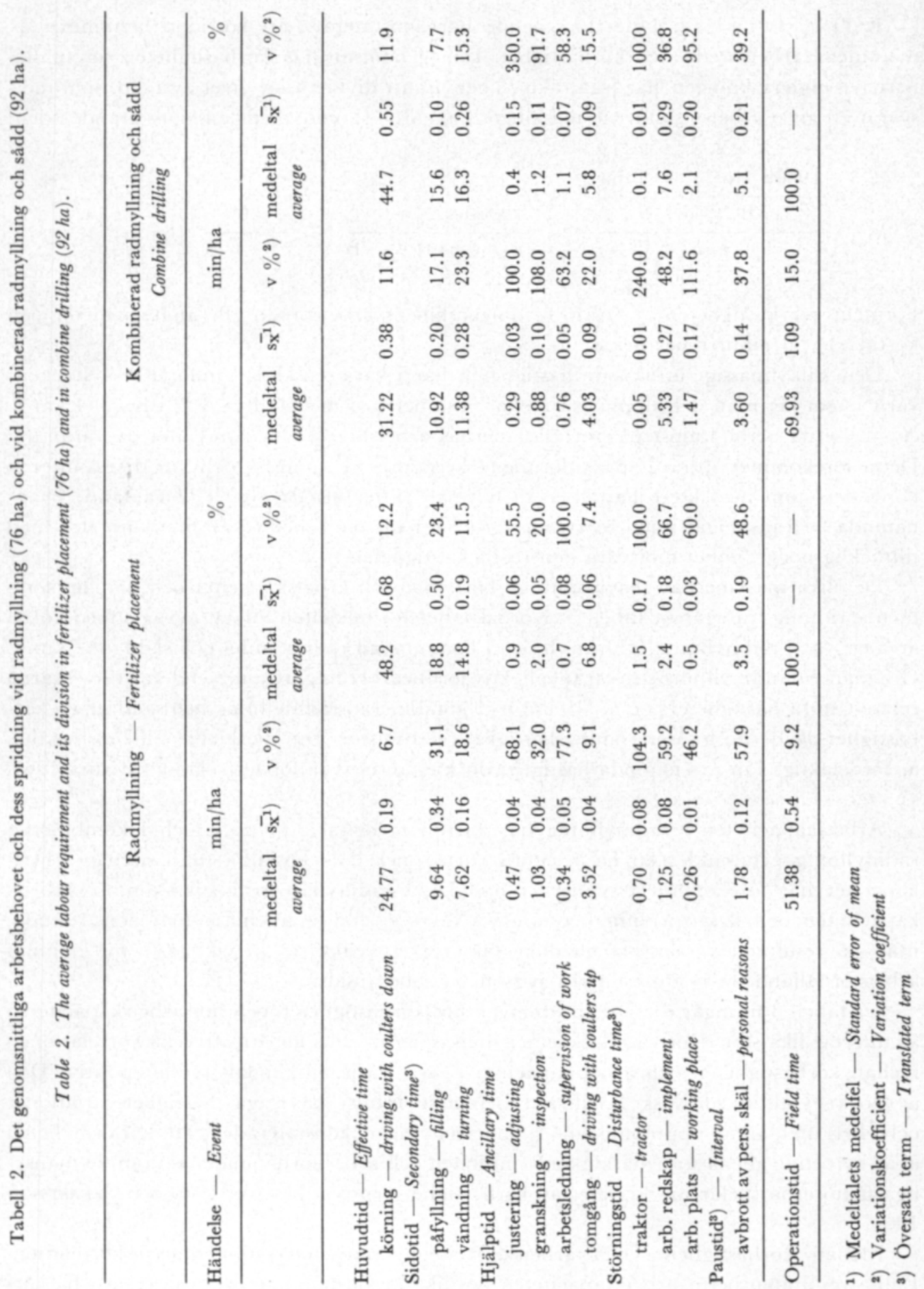




\section{Faktorer som påverkar arbetskapaciteten}

K ö rhastigh e t. I det föregående har konstaterats, att körtiden bestämmes av maskinens arbetsbredd och körhastighet. Den genomsnittliga körhastigheten för maskinerna i undersökningen har framräknats genom att dividera ett givet avstånd, som motsvarar ett givet arbetsresultat vid maskinens fulla arbetsbredd, med den motsvarande tiden:

$$
\mathrm{v}=\frac{\frac{10000\left[\mathrm{~m}^{2}\right](=1 \mathrm{ha})}{\mathrm{B}[\mathrm{m}]}}{\mathrm{T}_{\mathrm{k}}[\mathrm{min}]}=\frac{10000[\mathrm{~m}]}{\mathrm{T}_{\mathrm{k}}[\mathrm{min}] \times \mathrm{B}}=\frac{600}{\mathrm{~T}_{\mathrm{k}} \times \mathrm{B}}[\mathrm{km} / \mathrm{h}]
$$

Formeln ger hastigheten (v) i km/h, då maskinens arbetsbredd (B) anges i meter och körtid $\left(\mathrm{T}_{\mathbf{k}}\right)$ i minuter per hektar.

Den kalkylmässigt uträknade hastigheten har i varje enskilda jämförelse (4 stycken) varit något lägre än den uppmätta reella hastigheten, i medeltal ca $4 \%$ eller $0.4 \mathrm{~km} / \mathrm{h}$. Avvikelserna beror främst på, att maskinernas arbetsbredd ofta köres litet på varandra. Detta förekommer speciellt på kilformiga åkerfigurer. I ändorna och vid dikeskanterna köres dessutom med lägre hastighet än normalt. Efter att ha tagit i betraktande ovannämnda begränsningar i den kalkylmässigt uträknade hastigheten kan man anse den med tillräcklig noggrannhet motsvara den reella hastigheten.

De olika maskinernas genomsnittliga hastighet och arbetskapacitet och där förekommen spridning framgår ur tabell 3. Körhastigheten i medeltal, vilken avvägts med körda arealer, var i radmyllning $9.17 \mathrm{~km} / \mathrm{h}$ och i kombinerad radmyllning och sådd $7.42 \mathrm{~km} / \mathrm{h}$. Om man vid radmyllning strävar till effektiv jordbearbetning, rekommenderar tillverkarna relativt stora hastigheter, t.o.m. $10 \mathrm{~km} / \mathrm{h}$. I kombinerad radmyllning och sådd är en körhastighet på $10 \mathrm{~km} / \mathrm{h}$ såsom såningshastighet relativt stor. Om maskinens billkonstruktion är fördelaktig, kan nyssnämnda hastighet dock ej anses vara för hög (jämför YAHIA 1960, s. 56).

Arbetskapaciteten i radmyllning har varit i medeltal $1.17 \mathrm{ha} / \mathrm{h}$ och i kombinerad radmyllning och sådd $0.86 \mathrm{ha} / \mathrm{h}$. Stora variationer $\mathrm{i}$ de enskilda maskinernas arbetskapacitet har förekommit i synnerhet hos Tume-radmyllare och Juko-kombi. Arbetskapaciteten och dess spridning bestämmes dock ej endast av maskinens konstruktion, utan på resultatet verkar många olika faktorer, av vilka såsom viktigaste må nämnas arbetsförhållandena och arbetarens personliga arbetsinsats.

Ur tabell 3 framgår det, att spridningen hos körhastigheten och hos arbetskapaciteten är ungefär lika stor. Korrelationskoefficienten, som använts för att uttrycka korrelationen mellan körhastigheten och arbetskapaciteten, är i varje enskilt fall tydligt positiv. Den är dock ej alltid statistisk signifikant beroende främst på ringa hastighetsvariationer och/eller litet antal upprepningar. I undersökningen konstaterades, att körhastigheten ej är beroende allenast av maskinkombinationen och arbetsförhållandena, utan de mänskliga faktorerna spelar in vid valet av körhastighet (jämför Jonsson 1970 och SEFAstsson 1964).

Mellan körhastigheten och arbetskapaciteten råder en tydlig kausal korrelation. Enligt resultaten beror arbetskapaciteten hos lika breda maskiner dock ej endast på körhastigheten. De faktorer, som verkar på arbetskapaciteten ser i grund och botten ut att 
Tabell 3. Korrelationen mellan körhastigheten och arbetskapaciteten vid radmyllning och kombinerad radmyllning och sâdd.

Table 3. Labour output in relation to speed in fertilizer and combine drilling.

\begin{tabular}{|c|c|c|c|c|c|c|}
\hline \multirow[t]{2}{*}{$\begin{array}{l}\text { Arb. redskap } \\
\text { Implement }\end{array}$} & \multicolumn{2}{|c|}{$\begin{array}{l}\text { Hastighet } \\
\text { Speed }\end{array}$} & \multicolumn{2}{|c|}{$\begin{array}{l}\text { Arb. kapacitet } \\
\text { Out put of work }\end{array}$} & \multirow[t]{2}{*}{$\begin{array}{l}\text { Korr.k. } \\
\text { Corr.c. }\end{array}$} & \multirow[t]{2}{*}{$\begin{array}{l}\text { Upprepningar } \\
\text { Repetitions }\end{array}$} \\
\hline & $\mathrm{km} / \mathrm{h}$ & $v \%^{1}$ & $\mathrm{ha} / \mathrm{h}$ & v $\%^{1}$ & & \\
\hline \multicolumn{7}{|l|}{ Radmyllare } \\
\hline \multicolumn{7}{|l|}{ Fertilizer drills } \\
\hline Juko-15 & 9.30 & - & 1.30 & - & - & 1 \\
\hline Jussi-Junkkari & 11.40 & 0.1 & 1.32 & 8.0 & +0.89 & 2 \\
\hline RM-300 & 9.39 & 8.5 & 1.22 & 13.1 & +0.45 & 12 \\
\hline Tume-315 & 8.33 & 16.7 & 1.02 & 26.5 & $+0.80 * * *$ & 10 \\
\hline \multicolumn{7}{|l|}{ Kombimaskiner } \\
\hline \multicolumn{7}{|l|}{ Combine drills } \\
\hline Antti & 10.03 & 11.0 & 1.23 & 16.4 & +0.84 & 3 \\
\hline HS-MK-Combi & 6.59 & 9.0 & 0.86 & 11.2 & +0.24 & 6 \\
\hline Juko & 7.03 & 29.4 & 0.70 & 26.7 & $+0.85 * *$ & 6 \\
\hline Junnila & 6.99 & 16.9 & 0.80 & 19.4 & $+0.95 * * *$ & 6 \\
\hline Nasta-Tume & 9.01 & 7.2 & 0.87 & 7.3 & +0.77 & 4 \\
\hline Pisto & 9.28 & 9.0 & 0.76 & 16.1 & $+0.85^{* *}$ & 7 \\
\hline
\end{tabular}

1) Variationskoefficient

Variation coefficient

vara rätt så komplicerade och $\mathrm{i}$ vissa fall till sin verkan motsatta (t.ex. körhastighet och förarens ansträngning eller maskinens arbetsbredd och förmåga att svänga snabbt).

$\mathrm{P}$ å f y $11 \mathrm{n}$ ing. Den genomsnittliga påfyllningstiden har hos radmyllarna varit i medeltal $1.13-2.05 \mathrm{~min} / 100 \mathrm{~kg}$, i det att medeltalet utgör $1.82 \mathrm{~min} / 100 \mathrm{~kg}$. I fråga om kombimaskiner har lådorna påfyllts av $1-2$ man, vilket leder till, att tidsvariationerna per $100 \mathrm{~kg}$ varit större, $0.93-2.09 \mathrm{~min}$. Påfyllningen har varit effektivast, om den utförts av endast en pèrson. Påfyllningstidens medeltal är nämligen för en person $1.61 \mathrm{~min} / 100 \mathrm{~kg}$ och för två $1.27 \mathrm{~min} / 100 \mathrm{~kg}$, eller bara ca $25 \%$ och inte $50 \%$ mindre. Alla maskiner i jämförelsegruppen var inte precis likadana, varför på skillnaderna verkat även andra faktorer än jämförelsegruppens storlek. Resultatet överensstämmer med SıPILÄs (1969, s. 26) observationer. Hjälpkarlens betydelse bör enligt undersökningen ses såsom ett garanti för god arbetskvalitet och ej såsom minskande faktor av arbetsbehovet.

Vid granskning av enskilda påfyllningstider framgick det, att påfyllningstiden inte stigit i proportion till påfyllningsmängden. Analysering av korrelationen mellan påfyllningstiden och -mängden utfördes i sådana fall, där en person utfört påfyllningen. Korrelationen mellan påfyllningstiden $(\mathrm{cmin} / 100 \mathrm{~kg}$ ) och -mängden (säckar à $50 \mathrm{~kg} / \mathrm{på-}$ fyllningsgång) framgår ur figur 1 . Enligt denna råder mellan dessa negativ korrelation. 


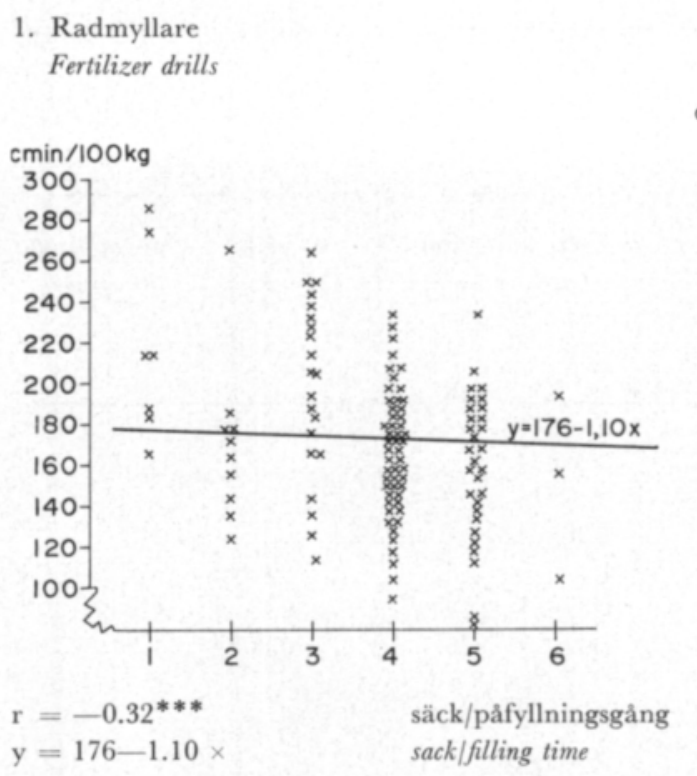
2. Kombimaskiner Combine drills

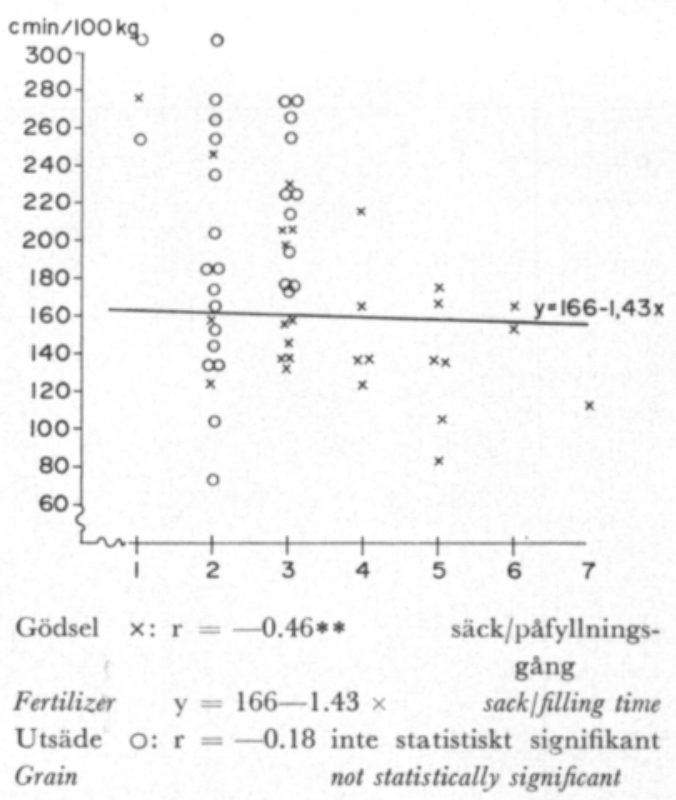

Figur 1. Korrelationen mellan påfyllningstiden $(\mathrm{cmin} / 100 \mathrm{~kg}$ ) och -mängden per påfyllningsgång hos radmyllare och kombimaskiner.

Fig. 1. Dependency of the filling time $(\mathrm{cmin} / 100 \mathrm{~kg})$ on the quantity filled per time in fertilizer and combine drills.

Angående gödsel är denna korrelation statistisk signifikant (med $1-5 \quad \%: s$ risk). Beträffande utsäde är korrelationen liten $(\mathrm{r}=-0.18)$ beroende främst på sålådans låga kapacitets utnyttjande.

Den korrelation, som konstaterats, betyder ej kausalitet, utan måste tolkas på följande sätt: Under påfyllningen avtar vid stigande påfyllningsmängder förberedelse- och avslutningstidernas relativa andel. Stora lådor är ofta vida, varför tömning av säckar i dylika maskiner är lättare än i maskiner med liten låda och smal öppning. I samma riktning verkar även omständigheten, att den sista säcken per påfyllning, vilken hos maskiner med liten låda förekommer relativt oftare än hos maskiner med stor låda, bör tömmas långsamt för att undvika överfyllning.

De påvisade korrelationerna är till sin storlek giltiga endast för undersökningsmaterialet. På grund av växlingar av olika faktorer är korrelationen inte stabil, utan varierar inom vissa gränser. Såsom fenomen kan denna korrelation dock generaliseras.

V ä n d n i n g a r. Vändningarnas antal per arealenhet är beroende av maskinens bredd, körsätt samt av teglängden. Dessa faktorer avgör dock ej allena den totala vändningstiden. Den tid, som åtgår för en enskild vändning har nämligen varierat i stor utsträckning. 
Fördelningen hos de olika maskinernas enskilda vändningstider framgår ur figur 2 . Frekvensdiagrammena avviker tydligt från den s.k. normalfördelningen. Detta beror delvis på, att körsättet i vändningarna varierat, m.a.o. frekvensdiagrammena består av flere frekvensdiagram på varandra. I de fall, upprepningarnas antal har varit stora, är frekvensdiagrammena till sin form ganska regelbundna. De lutar dock klart åt vänster och påminner sålunda om diagram i ackordarbete (jämför Pukкıla 1959, s. 218-219).

Skillnaden mellan den minsta och den största vändningstiden var hos HS-MK-Combi och Junnila synnerligen stor, nästan 2 min. Detta i samband med frekvensdiagrammens form påvisar, att de olika lantbrukspraktikanter, som fungerat såsom chaufförer, varit rätt oövade i sitt arbete. Denna omständighet har under hela undersökningen satt sin prägel på dessa maskiners resultat.

Enligt resultaten (figur 2) påverkar inte allena maskinens kopplingssätt till traktorn, 3-punktskopplad eller bokserad, maskinkombinationens vändningshastighet. En tydlig skillnad förelåg ej mellan de olika typerna. De långa bokserade maskinerna ser dock ut att vara $\mathrm{i}$ vändningarna långsammare än de andra. Chaufförens skicklighet påverkade däremot kraftigt enskilda vändningstider.

Övrig a faktorer. De här omnämnda arbetsskedena: körning, påfyllning och vändning utgör i medeltal ca $80 \%$ av arbetsbehovet vid radmyllning och vid kombinerad radmyllning och sådd. Resten utgöres huvudsakligen av tomgång, paus och olikaslags störningar.

Huvuddelen av tomgång, i medeltal ca $80 \%$, uppstod i samband med påfyllningen. Lådornas kapacitet har hos radmyllarna utnyttjats i medeltal till $70-80 \%$. Motsvarande tal hos kombimaskinerna är 65-90\% (gödsellådan) och 20-50\% (utsädeslådan). Talen utvisar, att hos kombimaskinerna var lådornas storlek $\mathrm{i}$ disproportion till de vanliga utsädes- och gödselmängderna (jämför tabell 1).

\section{Möjlighet att förbättra arbetskapaciteten}

I princip kan man förbättra radmyllarnas och kombimaskinernas arbetskapacitet på två huvudsätt:

— Genom att öka maskinens arbetsbredd och/eller körhastighet, d.v.s. genom att minska huvudtidens arbetsbehov.

- Genom att öka huvudtidens relativa andel av operationstiden medelst minskning av de övriga deltiderna, m.a.o. en allt större andel av operationstiden användes för produktivt arbete.

Naturligtvis bör man sträva till att använda bägge huvudmetoder samtidigt

Att minska körtiden genom att öka inom vissa gränser maskinens hastighet är förmånligare än att öka maskinens arbetsbredd. Stor vikt lägges härvidlag dock vid maskinens billkonstruktion. Genom förstoring av maskinens lådor och genom att göra lådorna sådana att de motsvarar arbetarnas normala räckvidd, kan man förbättra den för hand utförda påfyllningens arbetsprestation. En maskinell påfyllning ställer på lådorna egna specialfodringar. Till sin storlek borde lådorna stå i proportion till de använda utsädes- och gödselmängderna. En lösning på detta problem är ställbar mellanvägg mellan lådorna. 


$$
\begin{aligned}
& \text { 2.1. Juko-15 } \\
& \frac{\pi}{x}=39.3 \\
& \mathrm{~s}_{\mathrm{x}}=2.10 \\
& \mathrm{n}=47
\end{aligned}
$$

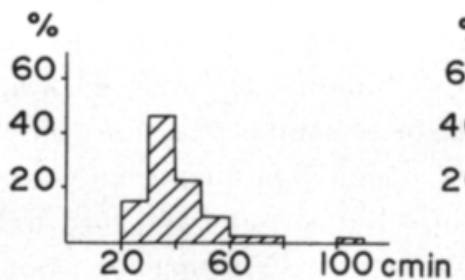

2.2. Jussi-Junkkari

$\bar{x}=22.7$

$\mathbf{s}_{\mathbf{x}}=0.59$

$\mathrm{n}=116$

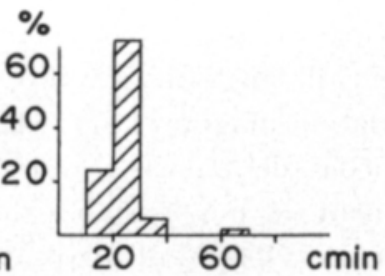

2.3. RM-300

$\bar{x}=30.8$

0.75

$\mathrm{n}=918$

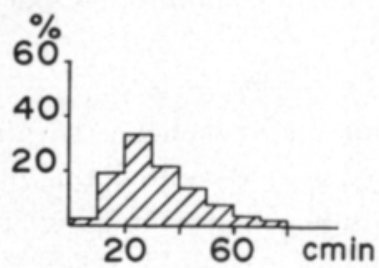

2.5. Antti

$\bar{x}=36.1$

$\mathbf{s}_{\mathbf{x}}=1.05$

$\mathrm{n}=261$

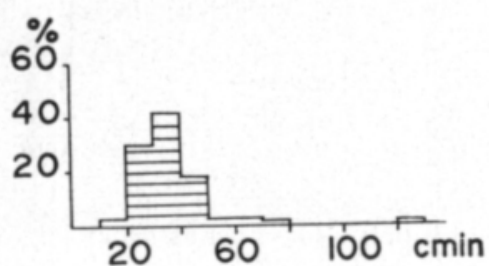

2.7. Juko

$$
\begin{aligned}
& \frac{\bar{x}}{\mathbf{x}}=30.7 \\
& \mathrm{~s}_{\overline{\mathbf{x}}}=0.77 \\
& \mathrm{n}=448
\end{aligned}
$$

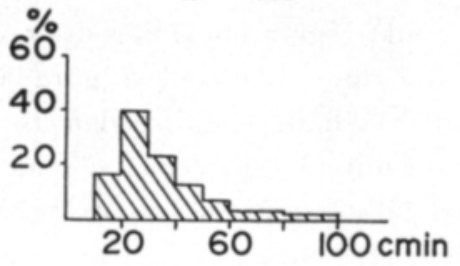

2.4. Tume- 315

$\bar{x}=42.6$

$\bar{x}=0.55$

$\mathrm{n}=490$

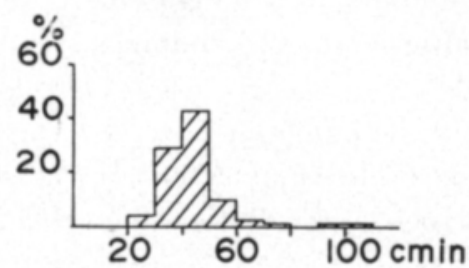

2.6. HS-MK-Combi

$$
\bar{x}_{-}=62.9
$$$$
\mathrm{s}_{\mathrm{x}}=1.75
$$$$
\mathrm{n}=540
$$

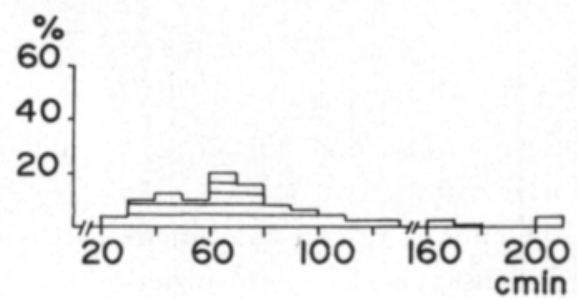

2.8. Junnila

$$
\begin{aligned}
& \overline{\mathrm{x}}=62.9 \\
& \mathrm{~s}_{\mathrm{x}}=1.89 \\
& \mathrm{n}=260
\end{aligned}
$$

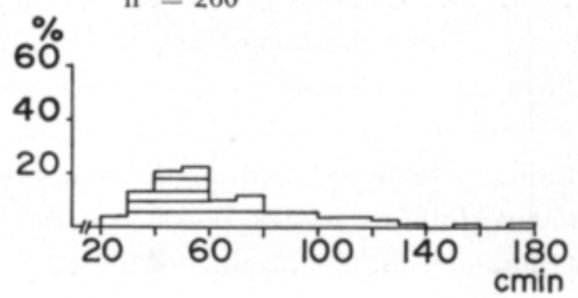



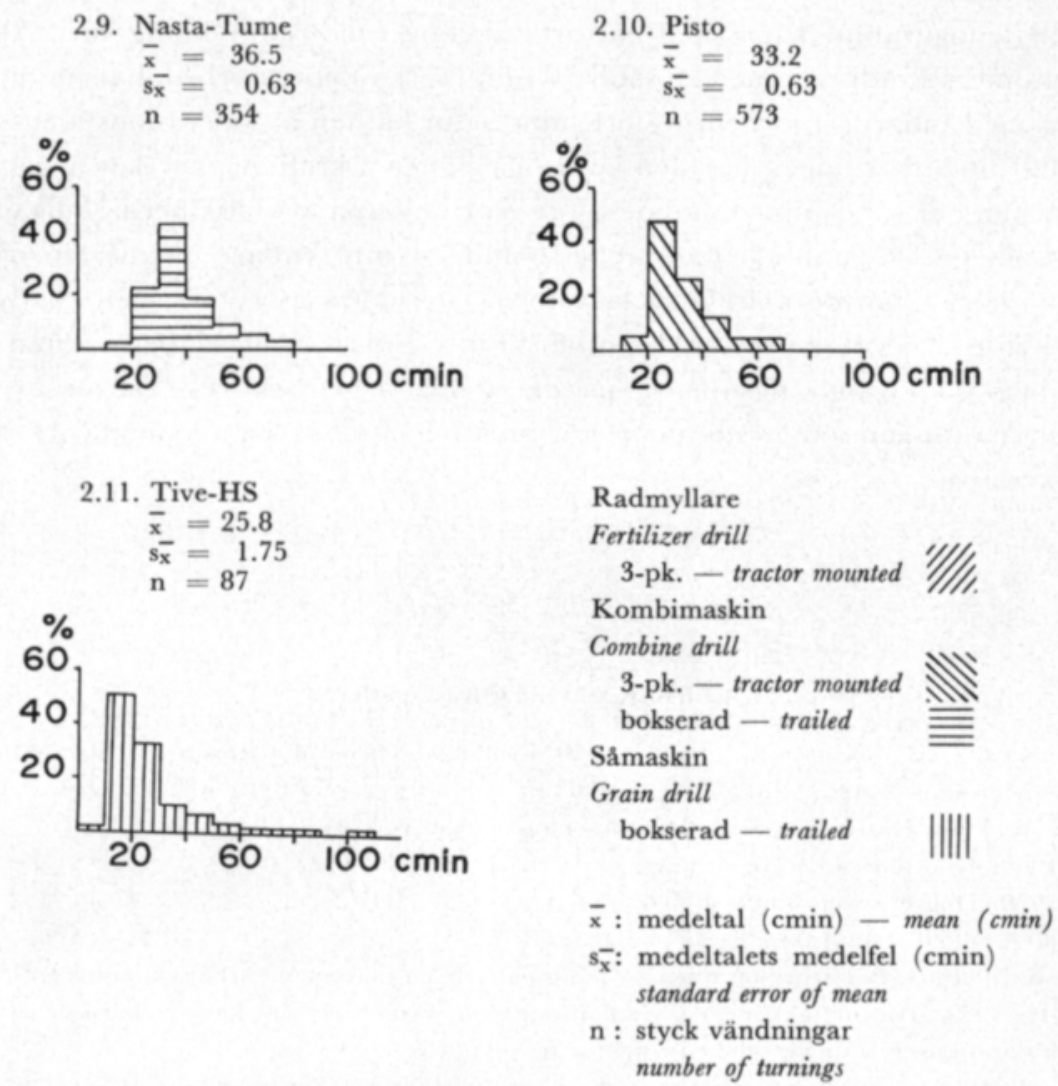

Figur 2. Fördelning av enskilda vändningstider i cmin (=1/100 min) för olika maskiner.

Fig. 2. Distribution of separate turning times in $\mathrm{cmin}(=1 / 100 \mathrm{~min})$ for different machines.

Att förstora lådorna minskar dessutom antalet påfyllningar och på detta sätt även tomgångstiden.

Vid minskning av störningstiden är maskinens funktionssäkerhet i nyckelställning. Man kan ej och bör ej ens försöka avlägsna paustiden helt. Man bör dock sträva till att minska arbetarnas behov till rekreation genom att underlätta utförandet av de tyngsta arbetsoperationerna (främst påfyllning) och genom att förbättra traktorns körkomfort. En provisorisk lösning på sistnämnda problem är användning av hörselskydd mot buller (jämför Jonsson 1970, s. 40).

\section{S a m m andrag}

För att klarlägga arbetsbehovet vid radmyllning och kombinerad radmyllning och sådd utfördes arbetsstudier åren 1968-70. Enligt undersökningen har arbetsbehovet varierat kraftigt och alla på arbetsbehovet påverkande faktorer har ej kunnat utredas 
tillräckligt noggrannt. I medeltal har arbetsbehovet vid radmyllning varit $51 \mathrm{~min} / \mathrm{ha}$ och vid kombinerad radmyllning och sådd $70 \mathrm{~min} /$ ha. I vartdera arbete har huvudtiden, d.v.s. körning med billarna i jorden utgjort mindre än hälften av operationstiden.

Enligt undersökningen har den körda hastigheten kraftigt påverkat arbetskapaciteten. Hastigheten har till och med omintetgjort verkningarna av maskinernas olika arbetsbredd. Körhastigheten fastställes enligt undersökningen inte enbart av maskinen och arbetsförhållandena, utan de mänskliga faktorerna är i detta avseende synnerligen betydande. De mänskliga faktorerna spelar dessutom in inte endast på hastigheten, utan även genom påfyllnings- och vändningstiderna på det totala arbetsbehovet. Därför är det sist och slutligen människan som bestämmer, huru nära den teoretiska maximala arbetskapaciteten man kommer.

\section{LITTERATURFÖRTECKNING}

Barnes, K. \& Casselman, T. \& Link, D. 1959. Field Efficiencies of 4-Row and 6-Row Equipment. Agricult. Engin. 3:148-150.

Jonsson, B. 1968. Kapacitetsprov med stora plogar. Arbetsekonomi 4:25-28.

- - 1969. Kombinerad radmyllning och sådd. Ibid. 2:11-12.

- - 1970. Högre avverkning vid plöjning. Ibid. 5:37-41.

PUKKILA, A. 1959. Työntutkimus. 319 s. Helsinki.

Sefastsson, J. 1964. Beror prestationen på mannen eller på maskinen. Arbetsekonomi 4:21-22.

SIPILÄ, H. 1969. Yhdistelmäkoneet ja rivilannoittimet Työtehoseuran käyttöteknisissä ja työmenetelmätutkimuksissa vuonna 1968. Työtehoseur. julk. 132:1 -49 .

YАнIA, M. 1960. Untersuchungen über den Einfluss höherer Drillmaschinen-Geschwindigkeit auf die Güte der Aussaat. 80 s. Göttingen. 